\title{
Development and validation of RP-HPLC method for determination of amoxicillin residues and application to NICOMAC coating machine
}

\begin{abstract}
The Cleaning Validation protocol plays an important role in the field of pharmaceutical industries; its main task is the verification of cleaning procedures to ensure that complete removal of product residues, degradation products, preservatives, excipients, cleaning agents and cross-contamination of the previous active ingredients. A new RP-HPLC method is evaluated for determination of Amoxicillin (AMO) residues in NICOMAC coating machine using Betabasic-C18 $(4.6 \mathrm{~mm} \times 250 \mathrm{~mm}) 5 \mu \mathrm{m}$ or equivalent, mobile phase of a mixture of $0.05 \mathrm{M}$ sodium dihydrogen phosphate: methanol $(95: 5 \mathrm{v} / \mathrm{v})$ adjusted to $\mathrm{pH}$ 4.4 with orthophosphoric acid at a flow rate of $1.5 \mathrm{~mL} / \mathrm{min}$, injection volume $100 \mu \mathrm{L}$ and $\mathrm{UV}$ detection at $230 \mathrm{~nm}$. The retention time of AMO is $6.292 \mathrm{~min}$ and the total run time is $7.0 \mathrm{~min}$. A Linear relationship is obtained in the range 0.03 to $6 \mathrm{ppm}$ with a correlation coefficient of 0.9989 , limit of detection $0.05 \mu \mathrm{gmL}^{-1}$ and limit of quantitation of $0.15 \mu \mathrm{gmL}^{-1}$. The overall recovery is $100 \pm 15 \%$; the relative standard deviation for precision and intraday precision is less than $2.0 \%$. The validation of the method is performed according to ICH guidelines and USP requirements for new methods, which include accuracy, precision, specificity, LOD, LOQ, robustness, ruggedness, linearity and range.
\end{abstract}

Volume 7 Issue 5 - 2018

\author{
Hassouna MEM,' Mohamed MA² \\ 'Chemistry Department, Beni-Suef University, \\ ${ }^{2}$ HIKMA group, Pharmaceutical Company, Egypt
}

Correspondence: Hassouna MEM, Chemistry Department, Faculty of Science 625I4, Beni-Suef University, Egypt, Fax +20822334-55I,Tel +2 0I22386I504,

Email mhassoune47@hotmail.com

Mohamad.hassona@science.bsu.edu.eg

Received: October 06, 2018 | Published: October 18, 2018

Keywords: amoxicillin, cleaning validation, RP- HPLC, stability indicating method, NICOMAC coating machine, ICH

Abbreviations: AMO, amoxicillin trihydrate; DIW, deionized water; HDPE, High density polyethylene; FDA, Food and drug administration; API, active pharmaceutical ingredient

\section{Introduction}

$\mathrm{AMO}$, is a semi-synthetic penicillin antibacterial drug derived from a fermentation product. Chemically, it is $(2 \mathrm{~S}, 5 \mathrm{R}, 6 \mathrm{R})-6-[[(2 \mathrm{R})-$ 2-Amino-2-(4-hydroxyphenyl) acetyl] amino]-3,3-dimethyl-7-oxo-4thia-1-azabicyclo [3.2.0] heptane-2-carboxylic acid trihydrate having a molecular formula of $\mathrm{C}_{16} \mathrm{H}_{19} \mathrm{~N}_{3} \mathrm{O}_{5} \mathrm{~S} .3 \mathrm{H}_{2} \mathrm{O}$ and its molecular weight is 419.4. AMO is a crystalline powder with white or almost white appearance. It is slightly soluble in water, very slightly soluble in ethanol $(96 \%)$, practically insoluble in fatty oils. It dissolves in dilute acids and dilute solutions of alkali hydroxides.

It may be represented by the structural formula ${ }^{1}$ as illustrated in (Figure 1). Amoxicillin is stable in the presence of gastric acid and is rapidly absorbed after oral administration. The effect of food on its absorption from tablets and suspension has been partially investigated. The 400 and $875 \mathrm{mg}$ formulations have been studied only when administered at the start of a light meal. However, food effect studies have not been performed with the 200 and 500mg formulations. Amoxicillin diffuses readily into most body tissues and fluids, except for brain and spinal fluid, especially when meninges are inflamed. Its half-life is 61.3 minutes. Most of the Amoxicillin is excreted unchanged in the urine; its excretion can be delayed by concurrent administration of probenecid. In blood serum, amoxicillin is approximately $20 \%$ protein-bound. It is similar to ampicillin in its bactericidal action against susceptible organisms during the stage of active multiplication. It acts through the inhibition of biosynthesis of cell wall mucopeptide. ${ }^{2}$

AMO is official in British Pharmacopeia (BP), ${ }^{1}$ European Pharmacopeia (EP) ${ }^{3}$ and United States Pharmacopeia (USP) ${ }^{4}$, they include HPLC method for its determination. It is still a limited number of analytical methods that are reported for the determination of AMO including kinetics degradation, ${ }^{5-7}$ spectrophotometric, ${ }^{8-13}$ UHPLC UPLC and mass spectrometry, ${ }^{14-19}$ thin layer chromatography (TLC) ${ }^{20-22}$ capillary electrophoresis, ${ }^{23-26}$ high performance liquid chromatography (HPLC), ${ }^{27-31}$ in vitro dissolution studies, ${ }^{32-36}$ amoxicillin residues in animal tissues using SPE-LC, ${ }^{37}$ SPE-cation exchange, ${ }^{38}$ in eggs using HPLC-FLD, ${ }^{39}$ or HPLC-MS ${ }^{40}$ and in commercial meat and milk samples ${ }^{41}$ using HPLC-FLD.<smiles>CC1(C)S[C@H]2[C@H](NC(=O)[C@@H](N)c3ccc(O)cc3)C(=O)N2[C@H]1C(=O)O</smiles>

Figure I Chemical structure of amoxicillin trihydrate.

According to the best of our knowledge there is no validated method for the determination of amoxicillin residues and application to cleaning machine in pharmaceutical industries. The present work describes the development and validation of an accurate and reliable RP-HPLC method for the determination of AMO residues and application to NICOMAC coating machine.

\section{Experimental}

\section{Materials and reagents}

Pure samples: Standard sample of AMO is kindly supplied by Hikma pharmaceutical industries company, Beni-Suef, Egypt with claimed purity of $98.2 \%$. 
Chemicals: Methanol HPLC-grade, sodium dihydrogen phosphate dihydrate and orthophosphoric acid are provided from (Scharlau, Spain).

Solvent preparation: Collect a sufficient quantity of fresh deionized water from the DIW loop in a suitable and clean container. Allow cooling to room temperature before use.

\section{Solutions}

Standard stock solutions of AMO $(1000 \mu \mathrm{g} / \mathrm{mL})$ : Weigh about the equivalent to $50 \mathrm{mg}$ of AMO from AMO (as trihydrate) working standard. Transfer completely to a $50-\mathrm{mL}$ volumetric flask with aid of $35 \mathrm{~mL}$ of deionized water. Shake for about 5 minutes, then complete to volume with deionized water.

Working standard solutions of AMO $(1.0 \mu \mathrm{g} / \mathrm{mL})$ : Accurately transfer $1.0 \mathrm{~mL}$ from the stock standard solution of AMO into $1000 \mathrm{~mL}$ volumetric flask, add diluent and sonicate to dissolve. Makeup to the mark with the same diluent and mix well. Inject into the chromatographic system. The chromatogram obtained is shown in (Figure 2).

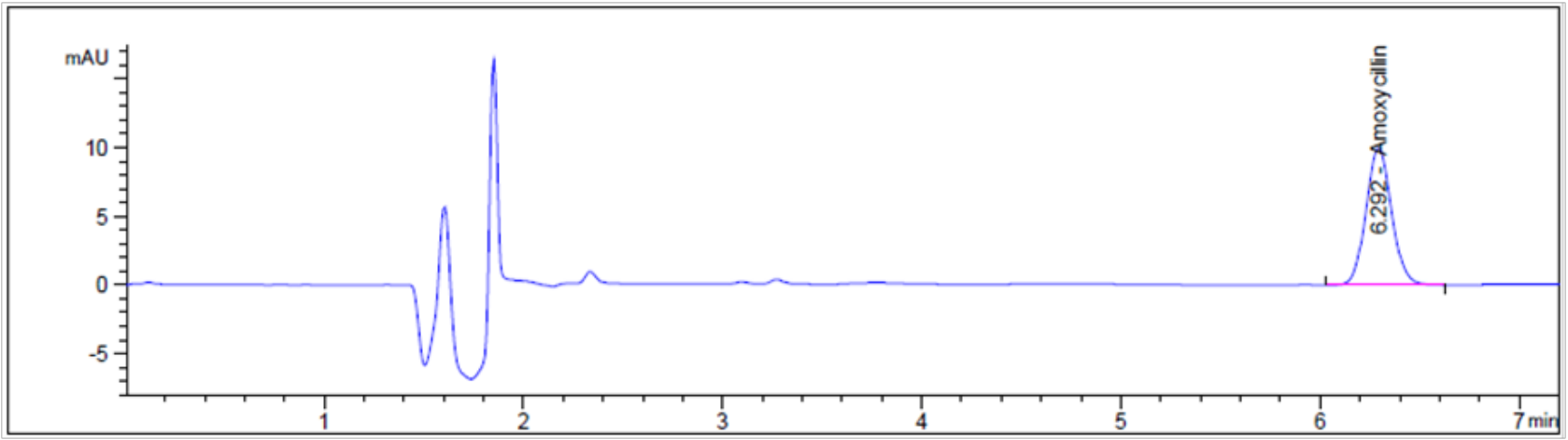

Figure 2 HPLC chromatogram of ( $1.0 \mu \mathrm{g} / \mathrm{mL})$ of AMO.

Instruments and chromatographic system: HPLC system (Agilent 1260 Infinity, Germany) instrument is equipped with an Agilent 1260 Infinity preparative pump (G1361A), Agilent 1260 Infinity DAD detector VL (G131SD), Agilent 1260 Infinity Thermostated column compartment (G1316A) and Agilent 1260 Infinity preparative Autosampler (G2260A) was performed using Betabasic - 4.6-mmx25$\mathrm{cm} ; 5 \mu \mathrm{m}$ packing L1. Adjust the flow rate to $1.5 \mathrm{~mL} / \mathrm{min}$ using UV Detector adjusted at $230 \mathrm{~nm}$ with column temperature $8^{\circ} \mathrm{C}$ and injection volume of $100 \mu \mathrm{L}$.
a. UV-1800 with high software UV-Probe 2.5 (Shimadzu model)
b. Mettler $\mathrm{pH}$ Meter.
c. Shimadzu analytical balance.
d. Ultra-sonic bath.
e. NICOMAC Coating Machine.

Mobile phase preparation: Dissolve about $10.1 \mathrm{~g}$ of dihydrogen sodium phosphate dihydrate in $900 \mathrm{~mL}$ of deionized water. Adjust the $\mathrm{pH}$ to $4.4 \pm 0.1$ with $\mathrm{H}_{3} \mathrm{PO}_{4}$. Complete the volume to $1000 \mathrm{~mL}$ using deionized water. Mix $950 \mathrm{~mL}$ of dihydrogen sodium phosphate buffer with $50 \mathrm{~mL}$ of methanol. Filter through a $0.45 \mu \mathrm{m}$ membrane filter.

Construction of standardization curves: Various aliquots of AMO in the range $0.03-6.0 \mu \mathrm{g} / \mathrm{mL}$, are independently transferred from their particular stock standard solutions into separate series of $100 \mathrm{~mL}$ volumetric flasks and volume is completed to the mark with the diluent and shaked well. Triplicate $100 \mu \mathrm{L}$ injections are executed for every concentration keeping the flow rate at $1.5 \mathrm{~mL} /$ min and the UV detection at $230 \mathrm{~nm}$. The chromatographic system is accomplished using the technique under chromatographic system. The chromatograms are assigned and area under peaks of AMO are determined and the calibration curves are conducted and the regression equations are processed.
Test preparation: To simulate the manufacturing equipment, SS316 plate $\left(5.08 \times 5.08 \mathrm{~cm}^{2}\right.$ area $)$ is cut from the SS-316 sheets and is used for all recovery studies. These studies are performed on the SS-316 plate $\left(5.08 \times 5.08 \mathrm{~cm}^{2}\right.$ area) by applying solutions of different concentrations (equivalent to $0.1 \mu \mathrm{g} / \mathrm{mL}, 1.0 \mu \mathrm{g} / \mathrm{mL}$ and $10 \mu \mathrm{g} / \mathrm{mL}$ ) of AMO by using a syringe and drying the plate in air. The plate is swabbed with a swab pre-moistened with methanol vertically and horizontally as shown in (Figure 3). Transfer the cotton swap to HDPE (high density polyethylene) bottle using clean forceps. Add $5 \mathrm{~mL}$ of deionized water to the bottle. Close with a white cap. Shake the bottle for about 5 minutes. Fill the vial then analyze by HPLC.

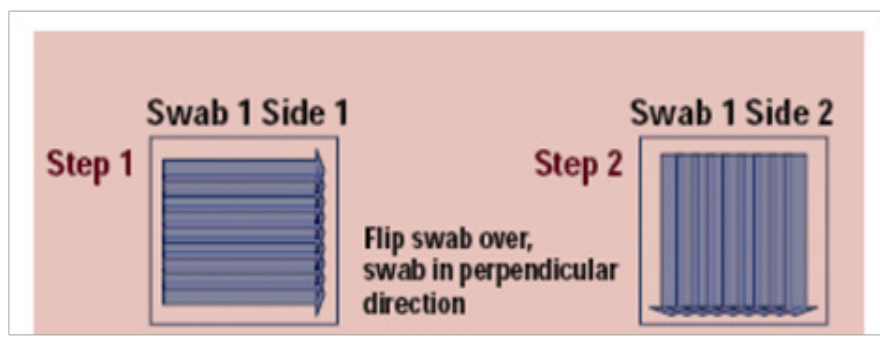

Figure 3 Swabbing pattern.

\section{Results and discussion}

\section{Methods development and optimization}

System optimization: The selection of mobile phase and the chromatographic system is dedicated to the good separation and resolution, so several conditions have been tested and comprehension different compositions of: $(100 \%)$ organic solvent, $(50: 50, \mathrm{v} / \mathrm{v})$; organic solvent: water. Every one of the solvents of the portable stage is filtered through $0.45 \mu$ membrane filter paper to expel particulate issue and degassed by sonication, additionally $(0.6,1.2,1.4$ and 
$1.5 \mathrm{~mL} / \mathrm{min}$ ) flow rates were attempted. To get the ideal wavelength of $20 \mu \mathrm{g} / \mathrm{mL}$ AMO, the system was optimized within range 200 $400 \mathrm{~nm}$ as showed in (Figure 4). In this manner, $230 \mathrm{~nm}$ is chosen as the most appropriate absorbance. Preparatory examinations included attempting $\mathrm{C} 18 \mathrm{~L} 1$ packing. The best developing system is $0.05 \mathrm{M}$ sodium dihydrogen phosphate: methanol $(95: 5 \mathrm{v} / \mathrm{v})$ adjusted to $\mathrm{pH}$ 4.4 with ortho phosphoric acid at a flow rate of $1.5 \mathrm{~mL} / \mathrm{min}$, injection volume $100 \mu \mathrm{L}$, the retention time of AMO is $6.292 \mathrm{~min}$ and the total run time is $7 \mathrm{~min}$. This selected developing system allows good separation with good $\mathrm{R}_{t}$ values without tailing of the separated bands and good theoretical plates.

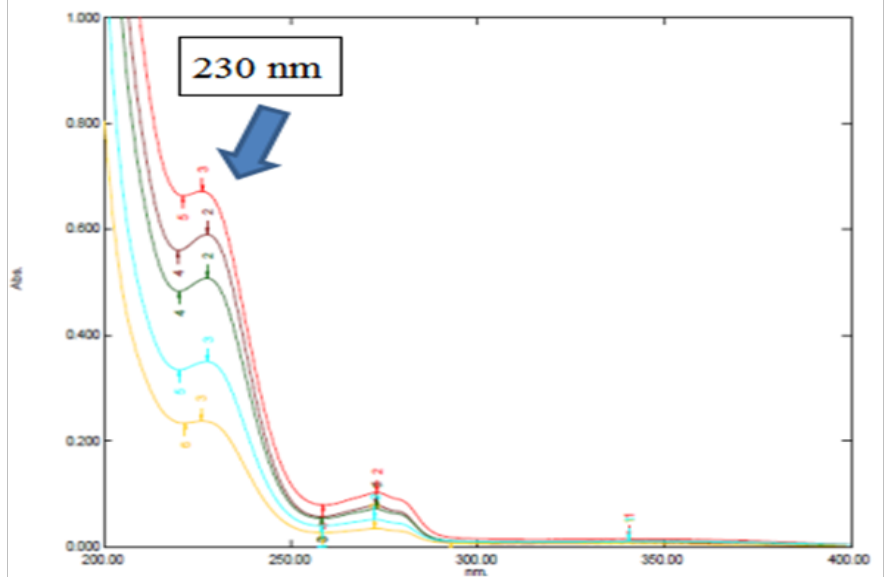

Figure 4 Linearity spectra of Amoxicillin using deionised water as a blank.
Cleaning validation for NICOMAC coating machine: Nowadays pharmaceutical products are manufactured in multi-use facility. FDA protects and promotes public health. Cleaning validation program ensures absence of residues of reaction byproducts and degrades from the previous process/product. The most appropriate cleaning procedure should be developed for the equipment to minimize the cross contamination and there is also necessity to develop and validate the sampling and chosen analytical methods for the compound(s) being cleaned for rinse and swab sampling. Along with taking samples, it is important to perform visual inspection as well to ensure the process acceptability.

Swab sampling: Direct surface sampling can be carried out in several ways, but the most common and widely accepted is swabbing. This involves wiping a predetermined area of the NICOMAC Coating Machine with a swab that has been moistened with a solvent bearing the contaminating compound. Usually the surface is wiped with one side of the swab using a certain number of strokes, then the swap is flipped and the surface is wiped at $90^{\circ}$ to the first series of strokes as shown in (Figure 3). Selection of swab is an important part during the cleaning validation program and to maximize the recovery. Two types of swabs are studied-Himedia (having circle head) and Texwipe (having flat head) as shown in (Figure 5). This method of sampling is the most commonly used and involved taking an inert material (eg., cotton wool) at the end of the probe (referred to as swab) and rubbing it methodically across the surface as machine body, hopper, guns, pipes and control panel (Figure 6) The results are represented in Table. 1.

Rinse sampling: A measured area of a cleaned surface is rinsed or solvent washed and the solvent is collected and tested for traces of contaminants as shown in (Figure 7).

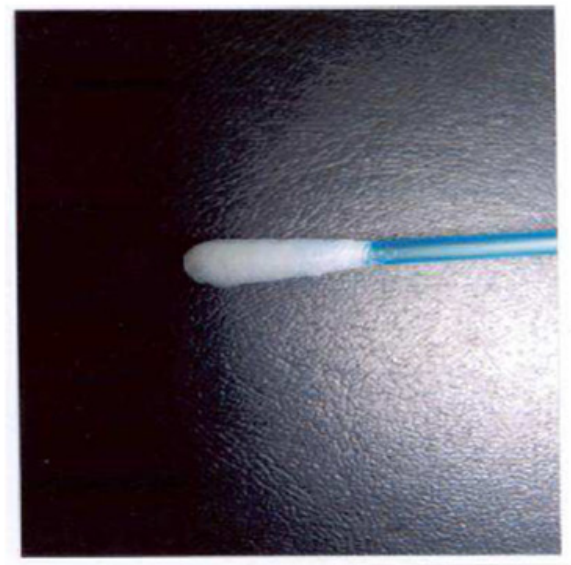

Swab - 1

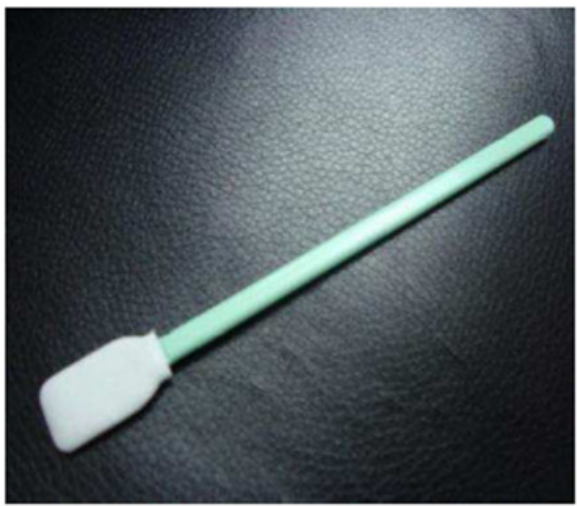

Swab - 2

Figure 5 Two types of swabs were studied-Himedia (having circle head) and Texwipe (having flat head). 

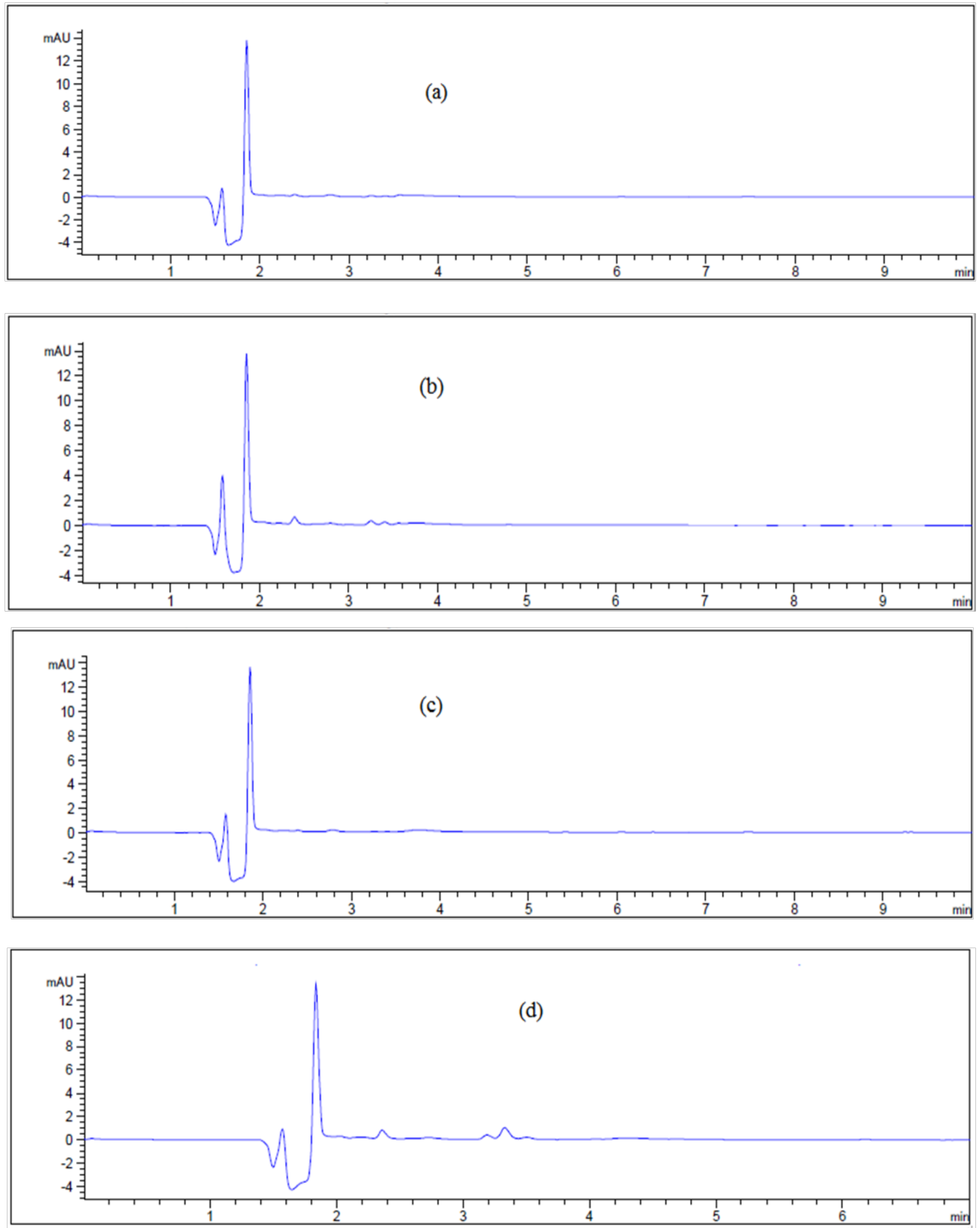

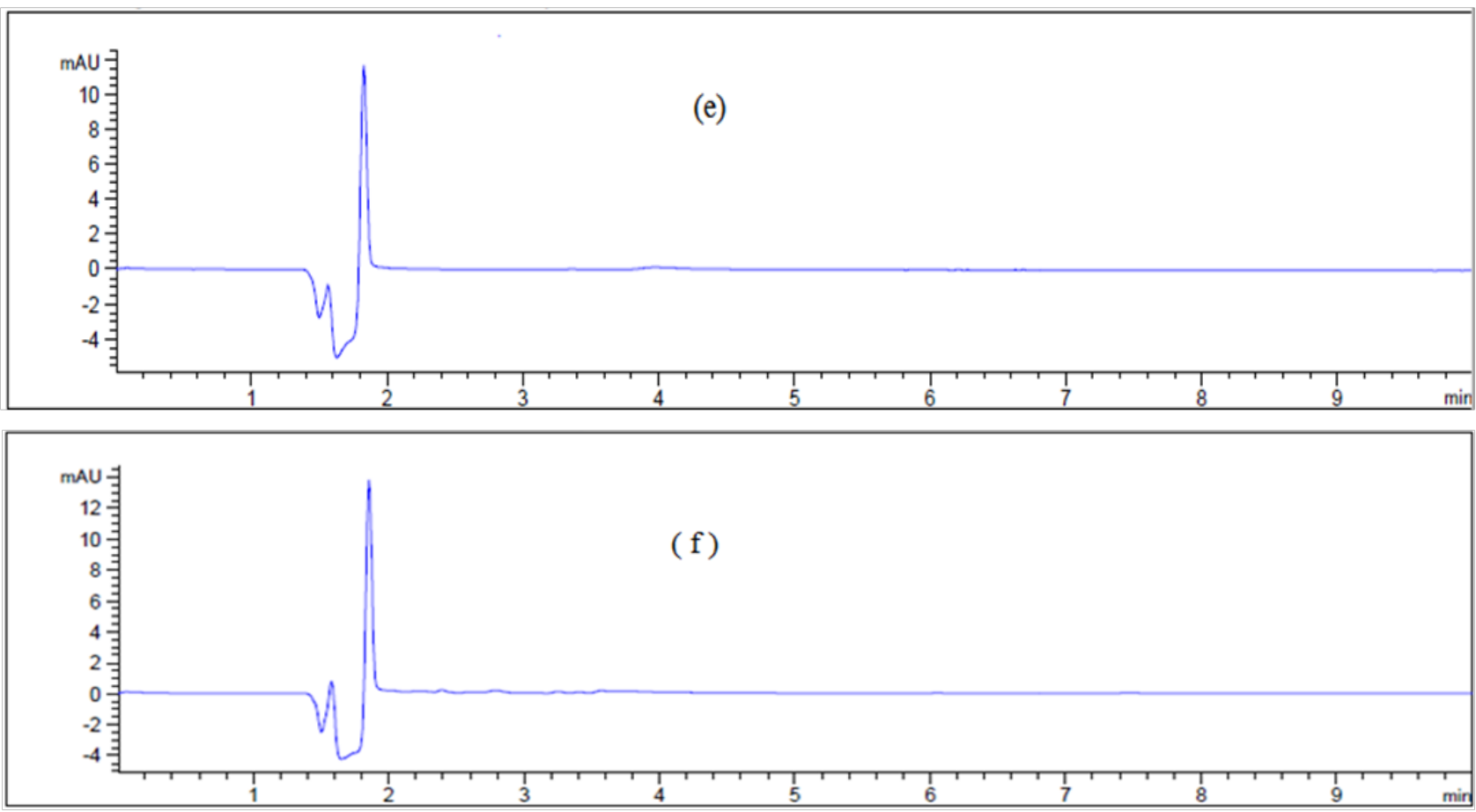

Figure 6 Chromatogram of (a) blank Texwipe swab, (b) Machine body, (c) hopper, (d), guns, (e) pips and (f) control panel.

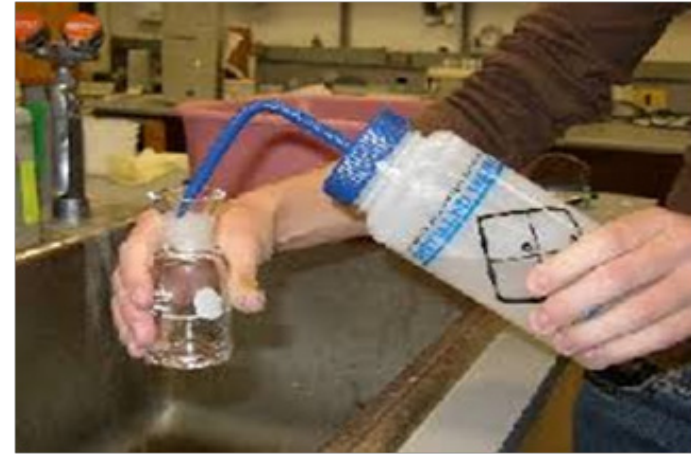

Figure 7 Rinse sampling method.

\section{Method validation}

Recently, we have published the validation of Cefaclor. ${ }^{42}$ The present method was, similarly, validated in accordance with ICH guidelines (ICH Q2R1), for system suitability, precision, accuracy, linearity, specificity, ruggedness, robustness, LOD and LOQ. ${ }^{43}$

\section{Linearity and range}

The linearity of the proposed method is obtained in the concentration range $(0.03-6.0 \mu \mathrm{g} \mathrm{AMO} / \mathrm{mL})$. Calibration curves are constructed by plotting the obtained peak areas against the corresponding concentrations. The obtained coefficient of regression is 0.9989 . Results of linearity are recorded in Table 2 .

\section{Precision}

Six injections from the working standard solution of AMO 1.0 $\mu \mathrm{g} /$ $\mathrm{mL}$ was successfully performed, where the RSD below $2.0 \%$ as mentioned in the below Table 2.

\section{LOD and LOQ}

Many methods are reported to verify LOD and LOQ but the important one is by using calibration curve and regression equation. Diluted standards of AMO solution of $0.05 \mu \mathrm{g} / \mathrm{mL}, 0.1 \mu \mathrm{g} /$ $\mathrm{mL}$ and $0.2 \mu \mathrm{g} / \mathrm{mL}$ are prepared for verification of the detection and quantification of the method. Each diluted standard solution is measured in triplicates as shown in (Figure 8). The residual standard deviation of a regression line or the standard deviation of $y$-intercepts of regression lines may be used as the standard deviation. LOD $=3.3 \times \sigma /$ slope and $\mathrm{LOQ}=10 \times \sigma /$ slope, where $\sigma=$ the standard deviation of the response as illustrated in Table 2.

\section{Accuracy and recovery}

Accuracy is studied by comparing the area of spiked solutions of $0.1,1.0$, and $10 \mu \mathrm{g} \mathrm{AMO} / \mathrm{mL}$ in solvent with the area of standard AMO in the range of $0.1,1.0$, and $10 \mu \mathrm{g} / \mathrm{mL}$. These data are presented in Table 3. The percent recovery is found to be in the range of $85 \%$ to $105 \%$.

\section{Lab variation method}

Ruggedness of the method indicates that the method remains unaffected by small variation in the method parameters as change from day to day, analyst to analyst and different codes in HPLC apparatus, thus the collected data are recorded in Table 4.

\section{Robustness}

Robustness indicates that the changes occurred to the method within the same laboratory. However, robustness can also be characterized as the probability to supersede the analytical method in different laboratories or under different conditions without the status of unusual differences in the obtained results as mentioned in Table 5. 


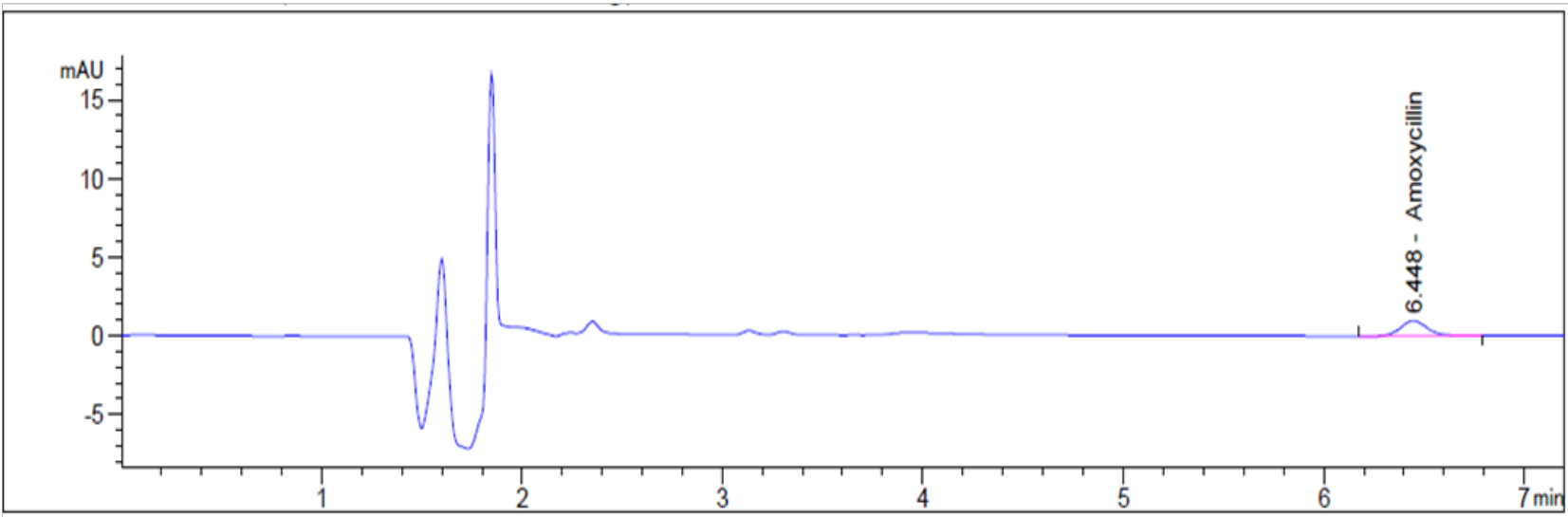

Figure 8 Chromatogram of detection limit.

Table I NICOMAC coating machine cleaning results by using HPLC

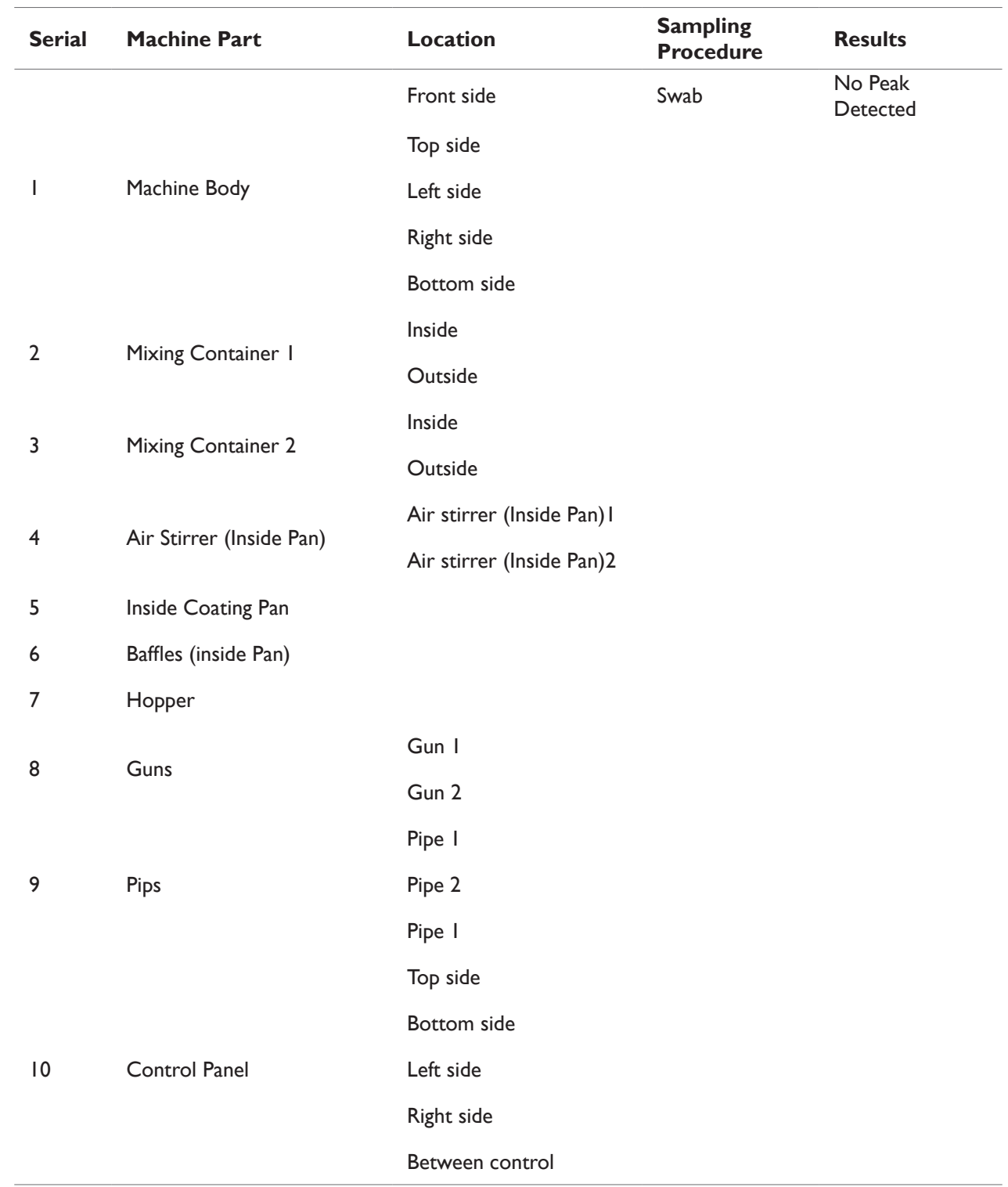


Table 2 Regression and validation parameters of the proposed HPLC method for determination of AMO

\begin{tabular}{ll}
\hline Parameter & AMO \\
\hline Linear & \\
range $(\mathrm{ppm})$ & $0.03-6$ \\
Slope & 86.6517 \\
Intercept & 4.0758 \\
Correlation coefficient & 0.9989 \\
LOD $^{\text {a }}(\mu \mathrm{g} / \mathrm{mL})$ & 0.05 \\
LOQ $^{\text {a }}(\mu \mathrm{g} / \mathrm{mL})$ & 0.15 \\
Repeatability & 0.101
\end{tabular}

${ }^{\mathrm{a}}$ Limit of detection $(3.3 \times \sigma /$ Slope $)$ and limit of quantitation (I0 $\sigma /$ Slope).

${ }^{\mathrm{b}}$ Repeatability for $\mathrm{n} \geq 5$, RSD $\leq 2$.

Table 3 Data of accuracy for AMO

\begin{tabular}{lll}
\hline Level (ppm) & Preparation & Amoxicillin (\%) \\
\hline & & Recovery \\
\hline 0.1 & I & 88.01 \\
& 2 & 86.7 \\
& 3 & 85.25 \\
& Mean & 86.65 \\
& 1 & 100.85 \\
& 2 & 100.72 \\
& 3 & 100.63 \\
& Mean & 100.73 \\
& I & 102.48 \\
& 2 & 102.47 \\
& 3 & 102.47 \\
& Mean & 102.47 \\
\hline
\end{tabular}

Table 4 Ruggedness of the method

\begin{tabular}{ll}
\hline Parameter(\%RSD) & AMO \\
\hline Intraday & 0.118 \\
Interday & 0.998 \\
Analyst to analyst & 0.114 \\
Column to column & 0.869
\end{tabular}

Table 5 Robustness of the method

\begin{tabular}{ll}
\hline Parameter(\%RSD) & AMO \\
\hline Flow rate change $( \pm 0.1 \mathrm{~mL} / \mathrm{min})$ & 1.770 \\
$\mathrm{pH}$ change of mobile phase $( \pm 0.2)$ & $\mathrm{I} .391$ \\
Wave length change $(230 \pm 1.0 \mathrm{~nm})$ & 0.332 \\
Column temperature change $\left(30^{\circ} \pm 5 \mathrm{C}\right)$ & 0.652 \\
\hline
\end{tabular}

\section{System suitability}

The system of the method can be achieved by verification of different factors as injection precision, resolution, theoretical plate and tailing factor, the results and calculated data are presented in the below Table 6 .

Table 6 System suitability testing parameters of the developed method

\begin{tabular}{|c|c|c|}
\hline Item & $\begin{array}{l}\text { Obtained } \\
\text { value }\end{array}$ & $\begin{array}{l}\text { Reference } \\
\text { values }\end{array}$ \\
\hline & AMO & \\
\hline Tailing factor & 1.07 & $\mathrm{~T} \leq 2$ \\
\hline Selectivity & 4 & $k^{\prime}>2$ \\
\hline Injection precision & 0.103 & RSD $\leq 1 \%$ \\
\hline Retention time $\left(R_{t}\right)$ & 0.04 & RSD $\leq 1 \%$ \\
\hline $\begin{array}{l}\text { Number of theoretical } \\
\text { plates(N) }\end{array}$ & 10366.59 & $N>2000$ \\
\hline
\end{tabular}

\section{Analyte stability}

Analyte stability is used to measure and verify that the solution remains stable under different storage conditions as room temperature against fridge and fresh sample, the obtained results are recorded in the below Table 7 .

Table 7 Result of stability of analytical solution

\begin{tabular}{ll}
\hline Condition & AMO \\
\hline Fridge $\left(2-8^{\circ} \mathrm{C}\right)$ & $98.22 \%$ \\
Room temperature $\left(25^{\circ} \mathrm{C}\right)$ & $97.10 \%$ \\
\hline
\end{tabular}

\section{Selectivity}

An analytical method is considered selective if its calculated data are not changed by other sample components to any significant extent. Compounds, other than analyte, which participate in the analytical signal, are called interfering compounds or interferents. The calculated data are mentioned in the Table 8 .

Light degeneration: Accurately weigh $50 \mathrm{mg}$ of AMO standard powder previously kept under sunlight for 48 hours and transfer to 50$\mathrm{mL}$ volumetric flask. Add $35 \mathrm{~mL}$ of the solvent, sonicate to dissolve. Accurately transfer $1.0 \mathrm{~mL}$ from this stock standard solution of AMO to $1000 \mathrm{~mL}$ volumetric flask, add diluent and sonicate to dissolve. Shake well and filter, then inject the vials into the HPLC system.

Heat treatment: Retain suitable quantity of AMO working standard in dry oven below $100^{\circ} \mathrm{C}$ for six hrs. until all moisture has been driven off and the weight is constant. After cooling to room temperature in a desiccator, accurately weigh $50 \mathrm{mg}$ of this powder and transfer to $50-\mathrm{mL}$ volumetric flask. Add $35 \mathrm{~mL}$ of solvent, sonicate to dissolve and complete to the mark with solvent. Accurately transfer an aliquot of $1.0 \mathrm{~mL}$ this of AMO into $1000 \mathrm{~mL}$ volumetric flask, add diluent and sonicate to dissolve. Make up to the mark with the same diluent and mix well. Filter as usual, furthermore inject the vials into HPLC system.

Acid treatment: Accurately transfer $1.0 \mathrm{~mL}$ from the standard stock solution of AMO into $1000 \mathrm{~mL}$ volumetric flask, add $100 \mathrm{~mL}$ of $0.1 \mathrm{M}$ 
$\mathrm{HCl}$ furthermore store the acidified solution at warm place for one day. Makeup to the mark. Shake well and filter, then inject the vials into HPLC system.

Alkaline treatment: Accurately transfer $1.0 \mathrm{~mL}$ from the standard stock solution of AMO into $1000 \mathrm{~mL}$ volumetric flask, add $100 \mathrm{~mL}$ of $0.1 \mathrm{M}$ sodium hydroxide then keep the basic solution at room temperature for $24 \mathrm{hr}$. Shake well and filter, then inject the vials into the HPLC system.

$\mathrm{H}_{2} \mathrm{O}_{2}$ degradation: Accurately transfer $1.0 \mathrm{~mL}$ from the standard stock solution of AMO into $1000 \mathrm{~mL}$ volumetric flask, add $75 \mathrm{~mL}$ of $3.0 \% \mathrm{H}_{2} \mathrm{O}_{2}$ then keep at room temperature for two days. Shake well and filter, then inject the vials into the HPLC system.

Table 8 Results of analysis of forced degradation study samples using proposed method, indicating percentage degradation of AMO

\begin{tabular}{lllll}
\hline \multirow{2}{*}{ Name } & Amoxicillin & & & \\
\cline { 2 - 4 } & Effect & Observed $\mathbf{~}_{\mathbf{R}}$ & Peak area & Degradation \% \\
\hline \multirow{2}{*}{ Without effect (control) } & 6.292 & 89.83479 & - \\
& Oxidation effect & 6.254 & 79.9876 & 10.96 \\
& Alkali effect & 6.266 & 74.6756 & 16.87 \\
& Acid effect & 6.281 & 85.2454 & 5.10 \\
& Light effect (Sun light) & 6.289 & 86.2132 & 4.03 \\
& Heat effect & 6.283 & 87.8778 & 2.17 \\
\hline
\end{tabular}

\section{Conclusion}

The proposed RP-HPLC method for the determination of AMO residues in NICOMAC coating machine is precise, specific, accurate and simple and may be successfully applied to quality control analyses during cleaning validation activity as well as routine cleaning programs. Swab recovery study is successfully developed and satisfactory results have been obtained. The results of forced degradation undertaken according to the (ICH) guidelines revealed that the method is selective and can be used for regular routine analysis and stability studies.

\section{Compliance with ethical standards}

\section{Funding}

No funding.

\section{Ethical approval}

This article does not contain any studies with animals performed by any of the authors.

\section{Acknowledgements}

The authors are thankful to the Publishers of the Journal of Analytical \& Pharmaceutical Research, MedCrave Group for the publication gift provided.

\section{Conflict of interest}

All authors declare that they have no conflict of interest.

\section{References}

1. British Pharmacopoeia. Stationary Office, Medicines and Healthcare Products Regulatory Agency. London; 2017.

2. https://www.fda.gov/downloads/Drugs/DevelopmentApprovalProcess/ DevelopmentResources/UCM205893
3. European Pharmacopeia. $8^{\text {th }}$ edition. 2014.

4. The United States Pharmacopoeia Convention Inc. The United States Pharmacopoeia. 38 ${ }^{\text {th }}$ Revision. 2015.

5. Chadha R, Kashid N, Jain DV. Kinetic studies of the degradation of an aminopenicillin antibiotic (amoxicillin trihydrate) in aqueous solution using heat conduction microcalorimetry. J Pharm Pharmacol. 2003;55(11):495-503.

6. Vahdat L, Sunderland VB. Kinetics of amoxicillin and clavulanate degradation alone and in combination in aqueous solution under frozen conditions. Int J Pharm. 2007;342(1-2):95-104.

7. Emad SE, Malay C. Degradation of amoxicillin, ampicillin and cloxacillin antibiotics in aqueous solution by the UV/ZnO photocatalytic process. J Haz Mat. 2010;173:445-449.

8. Wasan AA. Spectrophotometric Determination of Amoxicillin in Pharmaceutical preparations through diazotization and coupling reaction. Iraqi J Sci. 2012;53(4):713-723.

9. Prakash K, Raju PN, Kumari KS, et al. Spectrophotometric Estimation of Amoxicillin Trihydrate in Bulk and Pharmaceutical Dosage Form. EJournal of Chemistry. 2008;5(S2):1114-1116.

10. Quanmin L, Zhanjun Y. Study of Spectrophotometric Determination of Amoxicillin Using Sodium 1,2-Naphthoquinone-4-Sulfonate as the Chemical Derivative Chromogenic Reagent. Anal Lett. 2006;39(4):763775 .

11. Al-Abachi MQ, Haddi H, Al-Abachi AM. Spectrophotometric determination of amoxicillin by reaction with $\mathrm{N}, \mathrm{N}$-dimethyl-pphenylenediamine and potassium hexacyanoferrate(III). Anal Chim Acta. 2005;554(1-2):184-189.

12. Othman NS, AL-Saffar RS. Spectrophotometric Determination of Amoxicillin in Pharmaceutical Preparations. Int J Enhan Res Sci Technol \& Eng. 2015;4(6):167-173.

13. Singh DK, Maheshwari G. Spectrophotometric determination of penicillins in pure and pharmaceutical formulations using FolinCiocalteu reagent. Drug Test Anal. 2010;2(10):503-600. 
14. Tiphaine L, Dominique V, Nicolas T, et al. Simultaneous Determination of Eight $\beta$-Lactam Antibiotics, Amoxicillin, Cefazolin, Cefepime, Cefotaxime, Ceftazidime, Cloxacillin, Oxacillin, and Piperacillin, in Human Plasma by Using Ultra-High-Performance Liquid Chromatography with Ultraviolet Detection. Antimicrob. Agents Chemother. 2016;60(8):4734-4742.

15. Darshan VC, Daxesh PP, Jaivik VS, et al. Analysis of Amoxicillin and Clavulanic Acid by UPLC-MS/MS in Human Plasma for Pharmacokinetic Application. J of Modern Drug Discovery and Drug Delivery Research (JMDDR). 2015;2(3):1-10.

16. Cirić B, Jandrić D, Kilibarda V, et al. Simultaneous determination of amoxicillin and clavulanic acid in the human plasma by high performance liquid chromatography-mass spectrometry. Vojnosanit Pregl. 2010;67(11):887-892.

17. Khuroo AH, Monif T, Verma PR, et al. Simple, economical, and reproducible LC-MS method for the determination of amoxicillin in human plasma and its application to a pharmacokinetic study. $J$ Chromatogr Sci. 2008;46(10):854-861

18. Chaitanya KA, Chelladurai R, Jeevanantham S, et al. A Novel and HighThroughput Method for the Simultaneous Determination of Amoxicillin and Clavulanic Acid in Human Plasma by Liquid Chromatography Coupled with Tandem Mass Spectrometry. Int J Pharm Pharm Sci. 2012;4(3):648-652.

19. Yaxin F, Xiaojie W, Miao Z, et al. Rapid and Simultaneous Quantitation of Amoxicillin and Clavulanic Acid in Human Plasma and Urine by Ultra-Performance Liquid Chromatography Tandem Mass Spectrometry and Its Application to a Pharmacokinetic Study. Anal Sci. 2016;32:12691276.

20. Ghoulipour V, Shokri M, Waqif-Husain S. Determination of Ampicillin and Amoxicillin by High-Performance Thin-Layer Chromatography. Acta Chromatogr. 2011;23(3):483-498.

21. Hancu G, Simon B, Kelemen H, et al. Thin Layer Chromatographic Analysis of Beta-Lactam Antibiotics. Adv Pharm Bull. 2013;3(2):367371

22. Petkova V, Tsvetkova DD, Obreshkova DP, et al. Validation of TLC Densitometric Method for Quality Control of Amoxicillin in Dosage Drug Products. World Journal of Pharmacy and Pharmaceutical Sciences (WJPPS). 2014;3:995-1008.

23. Hancu G, Neacșu A, Papp LA, et al. Simultaneous determination of amoxicillin and clavulanic acid in pharmaceutical preparations by capillary zone electrophoresis. Braz J Pharm Sci. 2016;52(2):281-286.

24. Marra MC, Cunha RR, Muñoz RAA, et al. Single-run capillary electrophoresis method for the fast-simultaneous determination of amoxicillin, clavulanate, and potassium. J Sep Sci. 2017; 40(17):35573562 .

25. Hernández M, Borrull F, Calull M. Determination of amoxicillin in plasma samples by capillary electrophoresis. J Chromatogr B Biomed Sci Appl. 1999;731(2):309-315.

26. Injac R, Kočevar N, Štrukelj B. Optimized Method for Determination of Amoxicillin, Ampicillin, Sulfamethoxazole, and Sulfacetamide in Animal Feed by Micellar Electrokinetic Capillary Chromatography and Comparison with High-Performance Liquid Chromatography. Croat Chem Acta. 2009;82(3):685-694

27. Manzoor A, Suresh BG, Sathish KSA. Development and Validation of Amoxicillin by RP-HPLC Method in Bulk drug and Pharmaceutical dosage forms. Int J Chem Tech Res. 2011;3(3):1037-1041.
28. Tavakoli N, Varshosaz J, Dorkoosh F, et al. Development and validation of a simple HPLC method for simultaneous in vitro determination of amoxicillin and metronidazole at single wavelength. $J$ Pharm Biomed Anal. 2007;43(1):325-329.

29. Batrawi N, Wahdan S, Al-Rimawi F. A Validated Stability-Indicating HPLC Method for Simultaneous Determination of Amoxicillin and Enrofloxacin Combination in an Injectable Suspension. Sci Pharm. 2017;85(1):6.

30. Hsu MC, Hsu PW. High-Performance Liquid Chromatographic Method for Potency Determination of Amoxicillin in Commercial Preparations and for Stability Studies. Antimicrob Agents Chemother. 1992;36(6):1276-1279.

31. Jayakar B, Kumudhavalli MV, Chandira RM, et al. Method Development and Validation of Rp-Hplc Method for Simultaneous Determination of Amoxycillin and Potassium Clavulanate. Int J Pharm Tech Res. 2010;2(1):906-909.

32. Kassaye L, Genete G. Evaluation and comparison of in-vitro dissolution profiles for different brands of amoxicillin capsules. Afr Health Sci. 2013;13(2):369-375.

33. Silva RL, Souza RS, Teles ALB, et al. Comparative In Vitro Analysis of Dissolution Profiles of Pharmaceutical Formulations Containing Amoxicillin. Lat Am J Pharm. 2013;32(3):358-363.

34. Emara LH, Abdou AR, El-Ashmawy AA, et al. In Vitro Release Evaluation of Gastroretentive Amoxicillin Floating Tablets Employing a Specific Design of the Flow-Through Cell. Dissolut Technol. 2013.

35. Al-Tabakha MM, Fahelelbom KMS, Obaid DEE, et al. Quality Attributes and In Vitro Bioequivalence of Different Brands of Amoxicillin Trihydrate Tablets. Pharmaceutics. 2017;9(2):18.

36. Hailu GS, Gutema GB, Ali YS, et al. Comparative In vitro Bioequivalence Evaluation of Different Brands of Amoxicillin Capsules Marketed in Tigray, Ethiopia. Int J Pharm Sci Nanotech. 2013;6(1):1966-1971.

37. Luo W, Ang CY. Determination of Amoxicillin Residues in Animal Tissues by Solid-Phase Extraction and Liquid Chromatography with Fluorescence Detection. J AOAC Int. 2000;83(1):20-25.

38. Rose MD, Tarbin J, Farrington WHH, et al. Determination of penicillins in animal tissues at trace residue concentrations: II. determination of amoxicillin and ampicillin in liver and muscle using cation exchange and porous graphitic carbon solid phase extraction and high-performance liquid chromatography. Food Addit Contam. 1997;14(2):127-133.

39. Xie K, Zhao M, Guo H, et al. Determination and depletion of amoxicillin residue in eggs. Food Addit Contam Part A Chem Anal Control Expo Risk Assess. 2013;30(4):670-677.

40. Liu YN, Pang MD, Xie X, et al. Residue depletion of amoxicillin and its major metabolites in eggs. J vet Pharmacol Ther. 2016;40(4):383-391.

41. Irum A, Saeed H, Ali S, et al. Estimation of Amoxicillin Residues in Commercial Meat and Milk Samples. J Microbiol Biotech Food Sci. 2014;4(1):48-50.

42. Mahmoud AM, Amr HA, Abdelfatah MA, et al. Validation and Comparative In-vitro Dissolution Studies of Cefaclor in Their Powder for Oral Suspension Dosage Forms. Anal Chem Lett. 2018;8(1):88-103.

43. ICH, Q2 (R1). Validation of Analytical Procedures: Text and Methodology. ICH Harmonized Tripartite Guideline. 2005. 